\title{
THE EFFECTIVENESS OF MISOPROSTOL COMPARES TO OXYTOCIN IN MANAGEMENT OF RETAINED PLACENTA: AN EVIDENCE-BASED CASE REPORT
}

\author{
Indra Gunawan', Roni Andre Syahputra² \\ email: indrakabhuom@gmail.com
}

\begin{abstract}
Introduction: Retained placenta is one of major cause for postpartum haemorrhage. Various medication and routes of administration have been reported to increase spontaneous placenta delivery and prevent manual removal of placenta. Purpose of the study to compare the outcome between misoprostol and oxytocin in management of retained placenta.

Method: literature searching was done in 4 databases (Pubmed, EbscoHost, Cochrane and Scopus) with specific keywords, continued with article selection and critical appraisal.

Result: 5 randomized controlled trial articles were found match to eligibility criteria. 3 of 5 studies found that spontaneous placental delivery occurred more in misoprostol group than oxytocin group. Based on 2 studies, the NNT value of misoprostol are 3 compare to oxytocin group. 2 other studies found that no significant differences of spontaneous delivery of placenta in misoprostol and oxytocin group. 2 studies found that misoprostol had shorter time for spontaneous placenta delivery. However, 2 other studies also found that misoprostol had longer time for spontaneous delivery. 1 study also found that Misoprostol group have less blood loss than oxytocin group.

Conclusion: administration of misoprostol has better outcome in induce spontaneous placenta delivery, time needed for delivery and less blood loss volume compared to oxytocin.
\end{abstract}

Keywords: misoprostol; oxytocin; prolonged third stage labour; retained placenta

\section{INTRODUCTION}

Postpartum haemorrhage is the most common cause of maternal mortality in Indonesia and worldwide. ${ }^{1}$ In Indonesia, $30.3 \%$ of maternal mortality are caused by postpartum haemorrhage. Prolonged third stage labour or retained placenta is one of major cause for postpartum haemorrhage. ${ }^{2}$ Retained placenta define as a condition when a placenta didn't deliver after 30 minutes of active management or 60 minutes of physiological management of third stage labour. Retained placenta occur in $2-3.3 \%$ of vaginal delivery. ${ }^{3}$

Despite of those fact, there is still no standard of care for management of prolonged third stage labour. ${ }^{3}$ Manual removal of placenta (MROP) is currently the treatment of choice and the definitive treatment for retained placenta. However, MROP has more risk for infection (endometritis), haemorrhage, and traumatic uterine perforation. ${ }^{4}$

Various medication and routes of administration have been reported to increase spontaneous placenta delivery and prevent manual removal of placenta. Those medication called uterotonics agent. Uterotonics agent can stimulate the contraction of myometrium to induce the separation of placenta. ${ }^{3}$ World health organization (WHO) have recommended the use 
of uterotonics agent for retained placenta. ${ }^{5}$ Based on various research, oxytocin and misoprostol in one of the most promising and common uterotonics agent for management of retained placenta. ${ }^{3}$

\section{Case Illustration}

A 25 years old pregnant women (G1P0) at 38 weeks gestation was came to emergency obstetrics and gynaecology unit. The patient was delivered a viable male infant via vaginal delivery. After the delivery of infant (second stage of labour), 10 IU oxytocin was administrated via intramuscular injection in $1 / 3$ medial vastus

\section{Clinical question}

In women with retained placenta, does administration of misoprostol have better outcome in induce spontaneous delivery of placenta compared to oxytocin?

\section{METHODS}

The article searching was done in 4 databases including Pubmed, EBSCOHost, Cochrane and Scopus. The keywords or terms that has been use for article searching strategy are "retained placenta", "misoprostol", "oxytocin" and 'syntocinon'. The keywords were arranged with Boolean Method. Literature searching was done on November $27^{\text {th }}$ to $29^{\text {th }} 2020$.

Article selection consist of screening of title and abstract, removal of duplication, and article selection based on the full text. Selection of the article title, abstract, and full text are based on eligibility criteria. The article which cannot full pill the eligibility criteria will be excluded. lateralis muscle, but 30 minutes after the injection the placenta wasn't delivered yet. The physician though that the women had retained placenta. The ultrasonography (USG) before the delivery show normal placenta attachment that there was no placenta accrete, increta nor percreta. The patient doesn't have comorbid such as hypertension, diabetes, or infection. The patient have normal vital sign and mild bleeding $( \pm 150$ $\mathrm{ml}$ ). The physician wants to use uterotonic drugs to induce spontaneous delivery of placenta. But the physician confused which drugs that will have a better outcome between misoprostol or oxytocin.

The inclusion criteria of this study were randomized control trial (RCT) or systematic review/meta-analysis of RCT studies; women women with retained placenta and singleton pregnancy as study population; administration of misoprostol as the intervention group and oxytocin for the comparison; spontaneous delivery of placenta, time needed for placental delivery, or incident of manual removal placenta as the outcome. Meanwhile, the exclusion criteria of this study were not-accessible full text, unfinished studies and not using english or Indonesia language.

the critical appraisal tools that has been used in this study are based on Centre for EvidenceBased Medicine (CEBM) for RCT study which can be accessed through this link https://www.cebm.ox.ac.uk/files/ebm-

tools/rct.pdf.

\section{RESULTS}

Total of articles that match with the keywords are 187 articles from four database (Pubmed 23 
articles, EbscoHost 19 articles, Cochrane 33 articles, Scopus 112 articles). After the literature searching was done, the step continued with article selection. The illustration of article selecting is shown in PRISMA flowchart (Figure 1). In final, only 5 articles were included in this study. Those articles consist of 4 randomized controlled trial study (Rogers et al., 2007; Harara et al., 2011; Nazerr et al., 2016; Maher et al.,
2017) and 1 double-blind randomized controlled trial study (Najafian et al., 2018). The level evidence criteria are based on Oxford Centre for Evidence-based Medicine 2009 for therapy study. ${ }^{6}$ The characteristics of each study can be seen at Table 1. The article that has been selected will continue to be critically appraised in validity, importance, and applicability criteria.

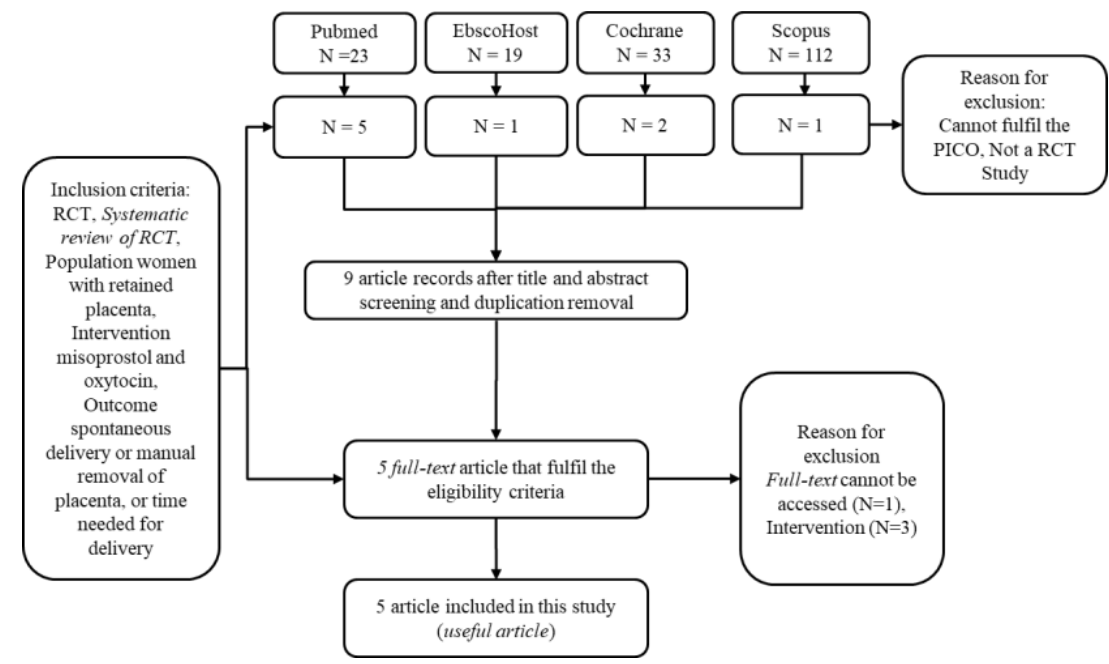

Figure 1 PRISMA Flowchart

Table 1 Study characteristics (Level of evidence)

\begin{tabular}{|c|c|c|c|c|c|}
\hline Authors & Population & Intervention & Outcome & Type of study & $\begin{array}{l}\text { Level of } \\
\text { Evidence }\end{array}$ \\
\hline $\begin{array}{l}\text { Rogers et } \\
\text { al., } 2007^{7}\end{array}$ & 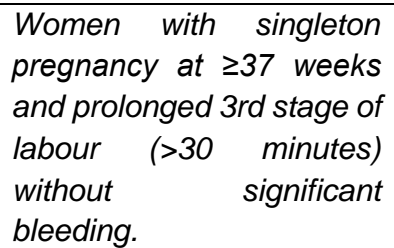 & $\begin{array}{l}\text { Misoprostol } 800 \mathrm{mcg} \\
\text { and Oxytocin } 50 \mathrm{IU} \\
\text { in } 30 \mathrm{ml} \text { saline } \\
\text { intraumbilical } \\
\text { injection }\end{array}$ & $\begin{array}{l}\text { - Spontaneous placenta } \\
\text { delivery or manual } \\
\text { removal of placenta } \\
\text { - Time needed for placenta } \\
\text { delivery }\end{array}$ & $\begin{array}{l}\text { Prospective } \\
\text { randomized } \\
\text { controlled trial }\end{array}$ & $1 b$ \\
\hline
\end{tabular}




\begin{tabular}{|c|c|c|c|c|c|}
\hline $\begin{array}{l}\text { Nazeer et } \\
\text { al., } 2016^{9}\end{array}$ & 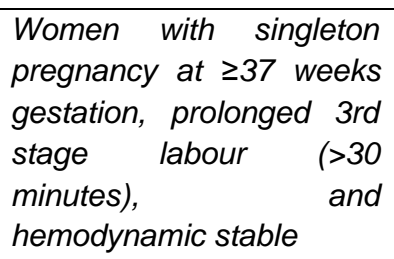 & $\begin{array}{l}\text { Misoprostol } 800 \mathrm{mcg} \\
\text { and Oxytocin } 50 \mathrm{IU} \\
\text { in } 30 \mathrm{ml} \text { saline } \\
\text { intraumbilical } \\
\text { injection }\end{array}$ & $\begin{array}{l}\text { - Spontaneous placenta } \\
\text { delivery or manual } \\
\text { removal of placenta } \\
\text { - Time needed for placenta } \\
\text { delivery } \\
\text { - Blood loss volume }\end{array}$ & $\begin{array}{l}\text { Randomized } \\
\text { controlled trial }\end{array}$ & $1 b$ \\
\hline $\begin{array}{l}\text { Maher et } \\
\text { al., } 2017^{10}\end{array}$ & $\begin{array}{l}\text { Woman with singleton } \\
\text { pregnancy and prolonged } \\
\text { 3rd stage of labour }(>30 \\
\begin{array}{l}\text { minutes) } \\
\text { hemodynamic stable. }\end{array}\end{array}$ & $\begin{array}{l}\text { Misoprostol } 400 \text { ug } \\
\text { sublingual and } \\
\text { Oxytocin } 30 \mathrm{IU} \text { in } 30 \\
\mathrm{mI} \text { normal saline } \\
\text { intraumbilical } \\
\text { injection }\end{array}$ & $\begin{array}{l}\text { - Spontaneous placenta } \\
\text { delivery or manual } \\
\text { removal of placenta } \\
\text { - Time needed for placenta } \\
\text { delivery }\end{array}$ & $\begin{array}{l}\text { Randomized } \\
\text { controlled trial }\end{array}$ & $1 b$ \\
\hline $\begin{array}{l}\text { Najafian et } \\
\text { al., } 2018^{11}\end{array}$ & $\begin{array}{l}\text { Pregnant women who } \\
\text { have a normal first and } \\
\text { second stage labour but } \\
\text { prolonged } 3 \text { rd stage of } \\
\text { labour (>30 minutes) and } \\
\text { hemodynamic stable. }\end{array}$ & $\begin{array}{l}\text { Misoprostol } 800 \mathrm{mcg} \\
\text { and Oxytocin } 50 \mathrm{IU} \\
\text { in } 30 \mathrm{ml} \text { saline } \\
\text { intraumbilical } \\
\text { injection }\end{array}$ & $\begin{array}{l}\text { - Spontaneous placenta } \\
\text { delivery or manual } \\
\text { removal of placenta } \\
\text { - Time needed for placenta } \\
\text { delivery }\end{array}$ & $\begin{array}{l}\text { Double-blind } \\
\text { randomized } \\
\text { clinical trial }\end{array}$ & $1 b$ \\
\hline
\end{tabular}

\section{Critical Appraisal}

\section{Validity}

All of 5 studies fulfil all the validity criteria that can be seen on Table 2. Randomization to allocate the participant has been done in all of 5 studies. In Rogers et al. study, the randomization method was prospective randomization in participants that come to two obstetrics units in Hong Kong from 2004-2005. In Harara et al. study, the participant randomly allocated into each group and the randomization was done by a computer-generated system. In Nazeer et al. study, the randomization was done by randomly allocating the participant into each group with an envelope method. In Maher et al. study, the participant was allocated randomly into each group by trial sequence in a computer-generated system that developed by statistician. In Najafian et al. study, the participant was allocated randomly into each group, the method of randomization was not mentioned in the article. In all of 5 studies mentioned that there were no significant characteristic differences between the two group $(p<0.05)$. In all of 5 studies also mentioned that all participant in each group was threated equally. In Rogers et al. study, each participant was given a prophylactic oxytocic drugs (Syntometrine $1 \mathrm{ml}$ IM or Syntocinon 10 unit IV) after the second stage of labour, the intervention was given if the placenta didn't deliver spontaneously in 45 minutes via intraumbilical injection with Pipingas technique. In Harara et al. study, the intervention was given to the participant if the placenta didn't deliver spontaneously in 25 minutes and if the separation occurred in the last 5 minutes the solution was discarded. The administration of the drug also via intraumbilical injection with Pipingas technique. In Nazeer et al. and Najafian et al. study, all of the intervention drugs was administrated via intraumbilical injection in $30 \mathrm{ml}$ normal saline with Pipingas technique, and except for the kind of the drug that administrated, all of the procedure are the same in each group participant. In Maher et al. study, apart from the kind of the drugs and administration route of the drugs, there was no different procedure between two group. In all of 5 studies, the number of participants that has been 
allocated into each group was same with the participants that entered analysis procedure. In Rogers et al. study, there were 1 failed catheterization sample in each group. In Maher et al study there were 3 failed administration drugs in Misoprostol group and 4 in oxytocin group. All that sample was count into failed treatment group. All of 5 studies were fulfil the blinding criteria. In Rogers et al and Nazeer et al study, the blinding was done only in the participants. In
Najafian et al. study, the blinding was done double in participant and person that administrated the drugs. In Harara et al, study although it didn't mention about blinding, but the study has objective outcome and all the drugs was administrated intraumbilical injection in $30 \mathrm{ml}$ saline, so it fulfils the blinding criteria. In Maher et al. study, the blinding was done by hide the assignment for a single patient in opaque sequenced envelopes.

Table 2 Validity of the study

\begin{tabular}{lccccc}
\hline Validity & Randomized & $\begin{array}{l}\text { Similar } \\
\text { Characteristics }\end{array}$ & $\begin{array}{l}\text { Equal } \\
\text { treatment }\end{array}$ & $\begin{array}{l}\text { Intention to } \\
\text { treat } \\
\text { analysis }\end{array}$ & Blinding \\
\hline Rogers et al., 2007 & + & + & + & + & + \\
Harara et al., 2011 & + & + & + & + & + \\
Nazeer et al., 2016 & + & + & + & + & + \\
Maher et al., 2017 & + & + & + & + & + \\
Najafian et al., 2018 & + & + & + & + & + \\
\hline
\end{tabular}

\section{Importance}

Importance of the studies can be calculated in all of 5 studies because all the article mentioned the exact number of intervention and outcome group. The importance of each study can be seen on Table 3. 3 of 5 studies (Rogers et al, Nazeer et al and Najafian et al) found that misoprostol had a better outcome in spontaneous placental delivery than oxytocin group. The rest of the studies (Harara et al and Maher et al) found there are no significant difference between misoprostol and oxytocin in induce spontaneous placental delivery. In Rogers et al and Najafian et al studies has significant relative risk, but in Nazeer et al studies the relative risk was not significant although the difference outcome between misoprostol and oxytocin group was significant $(p<0.05)$. The absolute risk reduction of misoprostol group from oxytocin group are $37.14 \%$ in Rogers et al study and $40.91 \%$ in Najafian et al study. These result show that administration of misoprostol can reduce $37.14 \%$ or $40.91 \%$ manual removal of placenta risk compare to administration of oxytocin. Number need to treat of misoprostol to reduce 1 manual removal of placenta compare to oxytocin are 3 in Rogers et al and Najafian study. These result means that if 3 patients with retained placenta or prolonged third stage of labour were threat with 
misoprostol it will reduce 1 manual removal of placenta procedure compare to if the patient were threat with oxytocin.

Aside from spontaneous delivery or manual removal of placenta, the outcome of these 5 studies also compare the time needed for placental delivery between misoprostol and oxytocin group. In Rogers et al. study the misoprostol group has longer time for spontaneous placenta delivery compare to oxytocin group, but the study did not mention whether the differences significant or not. The time recorded in Rogers et al. study was total 3rd stage of labour not only after injection of intervention drugs. In Maher et al. study also mentioned that misoprostol group has longer time for spontaneous placenta delivery compare to oxytocin, and the difference are significant. Otherwise, in Harara et al. and Nazeer et al study found that misoprostol group has shorter time for spontaneous placenta delivery compare to oxytocin group, and the difference are significant. In Nazeer et al. study also found that misoprostol group has significant less bleeding compare to oxytocin group.

\section{Applicability}

All of 5 articles/studies that used in this study was done in Asia country. 1 study (Rogers et al) was done in Hongkong, 2 studies (Harara et al and Maher et al) in Egypt, 1 study (Nazeer et al) in Pakistan, and 1 study (Najafian et al) in Iran. The subject in all of 5 studies are pregnant women with prolonged third stage of labour or retained placenta and hemodynamic stable. In Harara et al. study the subjects was women with preterm and a term singleton pregnancy ( $\geq 20$ weeks gestation), but in Rogers et al. and Nazeer et al. study the subjects was only women with a term singleton pregnancy ( $\geq 37$ weeks gestation). In Maher et al. and Najafian et al. study didn't mention about the subjects gestational age. Based on Coviello et al study there are no difference risk of retained placenta in Middle East race, Asian and Indonesian race. Gestational age $\geq 34$ weeks tend to have lower risk compare to 2427 weeks gestation. The patient in this case illustration is a Woman with 38 weeks singleton pregnancy has prolonged third stage of labour and hemodynamic stable. The characteristic of the participants of those 5 studies and patient in this study are similar so this research can be applied to patient in case illustration.

4 of 5 studies (Rogers et al., Harara et al., Nazeer et al., and Najafian et al.) are use intraumbilical injection of misoprostol and oxytocin, but 1 study (Maher et al.,) use sublingual misoprostol and intraumbilical injection of oxytocin. Intraumbilical injection has been applied in Indonesia but it needs skilled physicians or midwife or special training for intraumbilical injection. Misoprostol and oxytocin are common drugs that has been used widely in Indonesia. The preparation for misoprostol injection may be more difficult than oxytocin injection. Misoprostol only has tablet dosage form. Before it injected to umbilical vein, its need to be dissolve in normal saline under aseptic condition to reduce the risk for infection.

Administration of misoprostol can cause adverse effects. Adverse effect that can be appear such as shivering, fever, dizziness, headache, vomiting, abdominal pain. In Nazeer et al. study mentioned that there was no significant adverse effect appear in misoprostol group compare to 
oxytocin group. Only 1 patient in misoprostol

group that developed shivering and pyrexia. So,

it can be concluded that the

misoprostol administration

Table 3 Importance of the study

case will overcome the potential harms.

\begin{tabular}{|c|c|c|c|c|c|c|c|}
\hline Importance & $\begin{array}{l}\text { RR } \\
(95 \% \mathrm{CI})\end{array}$ & ARR $(95 \% \mathrm{Cl})$ & RRR & NNT (95\% Cl) & $\begin{array}{l}\text { Difference } \\
\text { between two } \\
\text { group } \\
\text { (p value) }\end{array}$ & $\begin{array}{l}\text { Time needed for } \\
\text { delivery }\end{array}$ & Blood loss \\
\hline $\begin{array}{l}\text { Rogers et al., } \\
2007\end{array}$ & $\begin{array}{l}0.54 \\
(0.31-0.92)\end{array}$ & $\begin{array}{l}37.14 \% \quad(36.87- \\
37.42)\end{array}$ & $46.43 \%$ & $\begin{array}{l}2.69 \\
(2.67-2.71) \\
=3\end{array}$ & $\begin{array}{l}\text { Misoprostol } \\
9 / 21 \\
\text { Oxytocin } \\
16 / 20 \\
(p<0.05)\end{array}$ & $\begin{array}{l}\text { Misoprostol } \\
83.9 \pm 25.9 \\
\text { Oxytocin } \\
67.7 .5 \pm 22.0\end{array}$ & \\
\hline $\begin{array}{l}\text { Harara et al., } \\
2011\end{array}$ & $\begin{array}{l}0.74 \\
(0.27-2.04)\end{array}$ & $\begin{array}{l}6.92 \% \\
(6.69-7.15)\end{array}$ & $25.71 \%$ & $\begin{array}{l}14.94 \\
(13.98-14.94) \\
=15\end{array}$ & $\begin{array}{l}\text { Misoprostol } \\
5 / 25 \\
\text { Oxytocin } \\
7 / 26 \\
(p>0.05)\end{array}$ & $\begin{array}{l}\text { Misoprostol } \\
7.0 \pm 2.2 \\
\text { Oxytocin } 13.1 \pm 3.76 \\
(p<0.001)\end{array}$ & \\
\hline $\begin{array}{l}\text { Nazeer et al., } \\
2016\end{array}$ & $\begin{array}{l}0.41 \\
(0.17-1.04)\end{array}$ & $\begin{array}{l}23.33 \% \\
(23.11-23.55)\end{array}$ & $58.33 \%$ & $\begin{array}{l}4.29 \\
(4.25-4.33) \\
=5\end{array}$ & $\begin{array}{l}\text { Misoprostol } \\
5 / 30 \\
\text { Oxytocin } \\
12 / 30 \\
(p<0.005)\end{array}$ & $\begin{array}{l}\text { Misoprostol } \\
8.5 \pm 1.23 \\
\text { Oxytocin } \\
15.55 \pm 2.84 \\
(p<0.005)\end{array}$ & $\begin{array}{l}\text { Misoprostol } \\
110 \mathrm{ml} \\
\text { Oxytocin } \\
210 \mathrm{ml} \\
(p<0.005)\end{array}$ \\
\hline $\begin{array}{l}\text { Maher et al., } \\
2017\end{array}$ & $\begin{array}{l}1.09 \\
(0.73-1.61)\end{array}$ & $\begin{array}{l}-2.93 \% \\
((-) 2.79-3.07)\end{array}$ & $-8.79 \%$ & $\begin{array}{l}34.13 \\
(32.61-35.79) \\
=35\end{array}$ & $\begin{array}{l}\text { Misoprostol } \\
33 / 91 \\
\text { Oxytocin } \\
32 / 96 \\
(p>0.05)\end{array}$ & $\begin{array}{l}\text { Misoprostol } \\
23.0 \pm 3.38 \\
\text { Oxytocin } \\
18.28 \pm 3.28 \\
(p<0.05)\end{array}$ & \\
\hline $\begin{array}{l}\text { Najafian et al., } \\
2018\end{array}$ & $\begin{array}{l}0.40 \\
(0.19-0.84)\end{array}$ & $\begin{array}{l}40.91 \% \\
(40.64-41.18)\end{array}$ & $60 \%$ & $\begin{array}{l}2.44 \\
(2.43-2.46) \\
=3\end{array}$ & $\begin{array}{l}\text { Misoprostol } \\
6 / 22 \\
\text { Oxytocin } \\
15 / 22 \\
(p<0.05)\end{array}$ & $\begin{array}{l}<5 \text { minute delivery } \\
\text { Misoprostol } 13.6 \% \\
\text { Oxytocin } \\
4.5 \% \\
(p>0.05)\end{array}$ & \\
\hline
\end{tabular}

\section{DISCUSSION}

Retained placenta define as a condition when a placenta didn't deliver after 30 minutes of active management or 60 minutes of physiological management of third stage labour. Retained placenta occur in $2-3.3 \%$ of vaginal delivery. Prolonged third stage labour (retained placenta) is one major cause of postpartum haemorrhage. Despite of those fact, there is still no standard of care for management of prolonged third stage labour. Various medication and routes of administration have been reported to increase spontaneous placenta delivery and prevent 
manual removal of placenta. Based on various research, oxytocin and misoprostol in one of promising drug for management of retained placenta. $^{3}$

Based on critical appraisal of those 5 RCT studies (Rogers et al., Harara et al., Nazerr et al., Maher et al. and Najafian et al.), It show that most of studies found that misoprostol was superior than oxytocin for retained placenta. 3 of 5 studies (Rogers et al., Nazeer et al., and Najafian et al.) found that spontaneous placental delivery occurred more in misoprostol group than oxytocin group. 2 other studies found that no significant differences of spontaneous delivery of placenta in misoprostol and oxytocin group. 2 studies (Harara et al. and Nazerr et al.) found that misoprostol had shorter time for spontaneous placenta delivery, but 2 other studies (Rogers et al. and Maher et al.) found that misoprostol had longer time for spontaneous delivery. In Nazeer et al. study, also found that Misoprostol group have less blood loss than oxytocin group.

All those 5 studies are randomized controlled trial study. Each study fulfils validity criteria for therapy studies. Despite all of 5 studies fulfil the validity criteria, each study still has weakness. In general, there are difference dosage of oxytocin and difference dosage and form of misoprostol drugs which has been use in those 5 studies. In Harara et al. it only used $20 \mathrm{IU}$ oxytocin which different from other studies that used $50 \mathrm{IU}$ oxytocin. In Maher et al. study, it used $400 \mathrm{mcg}$ sublingual misoprostol and $30 \mathrm{IU}$ oxytocin. Other 3 studies use $800 \mathrm{mcg}$ misoprostol and $50 \mathrm{IU}$ oxytocin that injected via umbilial vein. In Rogers et al study, it mentioned that they use (Syntometrine $1 \mathrm{ml}$ or Syntocinon 10
IU) for active management third stage of labour. Those two different drugs may confound the misoprostol or oxytocin injection. In Harara et al. study, it didn't differentiate preterm and term pregnancy analysis despite uterotonics response is less effective in preterm pregnancy. ${ }^{9}$ In Maher et al. and Najafian et al studies, both studies didn't mention gestational age and in Najafian et al. didn't mention singleton pregnancy. Others than Maher et al. study, 4 studies has small participants which range from 40-60 participants.

Currently, there is no standard of care for management prolonged third stage labour. WHO guidelines in 2009 recommend repeat active management of oxytocin injection dose or oxytocin injection via umbilical vein. ${ }^{5}$ Manual removal of placenta is the definitive treatment for retained placenta but it has high risk for infection and increased bleeding. ${ }^{4}$ After critically appraised the literature, we recommend, the use of intraumbilical injection of misoprostol for retained placenta other than oxytocin. But further trial and research that included large participants are needed to determine the safest and most effective management for retained placenta especially use misoprostol as an intervention.

\section{CONCLUSION AND RECOMMENDATION}

In women with prolonged third stage labour or retained placenta, administration of misoprostol has better outcome in induce spontaneous placenta delivery compared to oxytocin. Injection of misoprostol also has shorter time and less blood loss. Route of administration of misoprostol that superior to oxytocin is intraumbilical injection. Outcome for sublingual misoprostol doesn't have significant difference compare to intraumbilical 
oxytocin injection. We recommend, the use of intraumbilical injection of misoprostol for retained placenta other than oxytocin. However, further trial and research that included large participants are needed to determine the safest and most effective management for retained placenta especially use misoprostol as an intervention.

\section{REFERENCES}

1. Perkumpulan Obstetri dan Ginekologi Indonesia (POGI). Pendarahan pasca-salin. Jakarta: POGI. 2016.

2. Kementrian Kesehatan Republik Indonesia. Profil kesehatan Indonesia. Jakarta: Kementrian Kesehatan RI. 2014.

3. Patrick HS, Mitra A, Rosen T, Ananth CV, Schuster M. Pharmacologic intervention for the management of retained placenta: a systematic review and meta-analysis of randomized trials. Am J Obstet Gynecol. 2020 Sep 1;223(3):447.e1-447.e19.

4. Ely JW, Rijhsinghani A, Bowdler NC, Dawson JD. The association between manual removal of the placenta and postpartum endometritis following vaginal delivery. Obstet Gynecol. 1995 Dec;86(6):1002-6.

5. Russell RT. WHO guidelines for the management of postpartum haemorrhage and retained placenta. Hum Fertil. 2011 Jun;14(2):129-129.

6. Oxford Centre for Evidence-Based Medicine: Levels of Evidence (March 2009) - Centre for Evidence-Based Medicine (CEBM), University of Oxford [Internet]. [cited 2020 Dec 6]. Available from: https://www.cebm.ox.ac.uk/resources/levels-of-evidence/oxford-centre-for-evidence-based-medicine-levels-ofevidence-march-2009

7. Rogers MS, Yuen PM, Wong S. Avoiding manual removal of placenta: evaluation of intra-umbilical injection of uterotonics using the Pipingas technique for management of adherent placenta. Acta Obstet Gynecol Scand. 2007;86(1):48-54.

8. Harara R, Hanafy S, Zidan MSA, Alberry M. Intraumbilical injection of three different uterotonics in the management of retained placenta. J Obstet Gynaecol Res. 2011;37(9):1203-7.

9. Nazeer S, Rehman M, Tahir S, Saeed K, Gul A. Umbilical vein injection of misoprostol vs syntocinon in normal saline for the treatment of retained placenta: randomized control trial. :4.

10. Maher MA, Sayyed TM, Elkhouly NI. Different routes and forms of uterotonics for treatment of retained placenta: a randomized clinical trial. J Matern-Fetal Neonatal Med Off J Eur Assoc Perinat Med Fed Asia Ocean Perinat Soc Int Soc Perinat Obstet. 2017 Sep;30(18):2179-84.

11. Najafian A, Ghasemi M, Esfahani NH. Umbilical vein injection of misoprostol versus oxytocin for managing retained placenta after parturition: a randomized clinical trial. Int J Womens Health Reprod Sci. 2018 Jul 1;6:297-301. 